\title{
When Are Native Species Inappropriate for Conservation Plantings?
}

\author{
By Amy C. Ganguli, David M. Engle, Paul M. Mayer, and Samuel D. Fuhlendorf
}

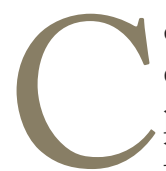

onservation agencies and organizations are generally reluctant to encourage the use of invasive plant species in conservation programs. Harsh lessons learned in the past have resulted in tougher screening protocols for nonindigenous species introductions and removal of many nonindigenous invaders from planting programs worldwide. Although the focus of screening and risk assessment programs has traditionally been on nonindigenous species, we present an example of a rapidly expanding native tree, eastern redcedar (Juniperus virginiana), widely used in planting programs throughout the United States and that should be screened for invasive potential. Intentional planting of eastern redcedar and fire suppression have converted many native grasslands to eastern redcedar woodlands. We recommend evaluating the invasive potential of all species proposed for use in conservation programs and present a conceptual framework for such an assessment.

Woody plants have invaded and expanded into grasslands and savannas worldwide, presenting an ecological and economic threat to many natural and managed ecosystems. A global investigation of 1,060 woody plant invasions revealed that accidental introductions represented a small proportion of the total invasions $(0.2 \%)$ whereas humanmediated introductions for amenity purposes (31\%), forestry (12\%), and agriculture (11\%) represented over half of the total invasive events. ${ }^{1}$ Many factors have been implicated in the spread of woody plants, including livestock introduction, fire suppression, and climate change. Factors presenting a barrier to woody plant expansion include lack of dispersal, ${ }^{2}$ life history traits (e.g., breeding system, shade tolerance, life span, morphology), ${ }^{3}$ soil properties, ${ }^{4}$ removal of herbivory, ${ }^{5}$ and fire. ${ }^{6}$

Conservation planting programs have come under scrutiny for using woody species that subsequently invade natural grasslands and riparian areas. Most of the attention has been placed on nonindigenous species such as Russian olive (Elaeagnus angustifolia), a species native to Eurasia that was introduced into the United States, and black wattle (Acacia mearnsii), a species native to Australia that was introduced to South Africa. In response to criticism from environmental and natural resource conservation communities (e.g., Olson and Knopf 19867), many US federal agencies and nongovernmental organizations turned from nonindigenous species to species native to North America for use in conservation planting programs. Although this change has merit, indiscriminant use of native species might pose risk comparable to using exotic species where encroachment by native woody species might also result in altered ecosystem structure and function.

\section{Origin of Tree Encroachment and Consequences to Grasslands History of Tree Planting in North American Grasslands}

Grasslands are among the most endangered ecosystems in North America. ${ }^{8}$ From the time of European settlement, the native flora and fauna of the North American grasslands have declined under an altered fire regime and landscape fragmentation resulting from conversion to cropland agriculture and human settlement. Tree invasion and tree planting projects are less obvious sources of fragmentation that followed settlement.

Tree planting in North American grasslands was initiated at settlement when pioneers from eastern states, who longed for the trees they left behind in the east, desperately needed timber for fuel and building materials. ${ }^{9}$ The United States government promoted tree planting through programs such as the Timber Culture Act of 1873, which granted homesteaders 160 acres provided trees were planted to 40 of those acres. ${ }^{9}$ In an effort to cope with the decline of soil and wildlife resources associated with unsustainable farming practices and drought of the 1930s and 1950s, tree planting was promoted by federal agencies (e.g., the Soil Conservation Service), which culminated in modern state and federal tree planting programs for conservation. Often, conservation 
programs promoted planting nonindigenous invasive woody plants to benefit wildlife habitat. ${ }^{7}$ Notable examples of invasive woody plants used in the United States include Russian olive, autumn olive (E. umbellata), multiflora rose (Rosa multiflora), and Japanese honeysuckle (Lonicera japonica). With increasing awareness of the negative ecological impacts of nonindigenous species, ${ }^{7}$ many conservation programs now promote planting native species. A native species promoted for conservation purposes outside its original habitat is eastern redcedar. Here, we examine the widespread use of eastern redcedar by conservation agencies, explain why this and other native species may not always be appropriate for conservation plantings, and describe a screening tool for selecting more appropriate species.

\section{Survey of Agency-Sponsored Tree Planting Programs}

We conducted a telephone survey of state operated nurseries disseminating seedlings in the contiguous United States in autumn of 2001 to identify how extensively eastern redcedar was used in agency-sponsored conservation planting programs and the primary uses for these seedlings. State nurseries, in contrast to private nurseries, function as low cost sources of plant materials for conservation purposes rather than for urban landscaping. Three states did not operate state nurseries and data from nine states were either inaccessible or not compiled. From the remaining 36 forest and conservation tree nurseries in the United States, we found that each year 22 state nurseries have annually sold eastern redcedar to public and private entities. Conservation districts in four states (Montana, Wyoming, Michigan, and Massachusetts) have purchased eastern redcedar seedlings from other state nurseries to distribute within their respective districts. The average number of seedlings distributed by states during 2001 was less than 128,000 , but some states sold markedly more (Table 1). In 2001, a year of below average seedling production in most states and seedling crop failure in Ohio and Indiana, $80 \%$ of the seedlings (1.842 million) were distributed in the Great Plains states. Nebraska, with a distribution program dating from 1926, distributed more than 1.2 million eastern redcedar and 350,000 Rocky Mountain juniper (Juniperus scopulorum) seedlings from the 1980s to the early 1990s. Seedling purchase from each of the 22 state nurseries has been open to any person or agency and for any use. The most common conservation uses for the seedlings were windbreaks and wildlife habitat plantings. Seedlings were used to a lesser extent for soil stabilization, living snow fences, shelterbelts, Conservation Reserve Program plantings, and mine reclamation. Seedling prices varied (Table 1), and purchases of seedlings in bundles of 100 or 1,000 were common and typically resulted in bulk discounts. Duration of the eastern redcedar seedling distribution programs ranged from $5 \mathrm{yr}$ to $76 \mathrm{yr}$, with the older programs located in the prairie biogeographical province.
Conservation Implications of Tree Planting Programs By contributing to woody plant expansion and fragmentation of prairie caused by woody plant encroachment, tree planting in the historically treeless North American prairies contradicts conservation of native ecosystems and species. Replacement of herbaceous species in grassland by eastern redcedar, despite it being a native species, alters plant and animal community composition, reduces plant species diversity, reduces wildlife and livestock forage production, and alters soil biogeochemistry. ${ }^{10-12}$ Our survey indicated that eastern redcedar was planted extensively in the United States and that the oldest distribution programs and greatest number of seedlings were distributed within the prairie states of the Great Plains. We believe these observations, along with the threatened status of prairies, ${ }^{8}$ warrant concern and a thorough examination of these practices.

While a form of wildlife habitat enhancement is indeed accomplished by tree planting in prairie ecosystems, many birds and mammals that use eastern redcedar for food and cover are habitat generalists that thrive at the expense of native prairie habitat specialists. ${ }^{10}$ Eastern redcedar is planted in some states specifically to support nonindigenous game species such as ring-necked pheasants (Phasianus colchicus), despite negative effects of eastern redcedar on sensitive sympatric native species such as the lesser prairie-chicken (Tympanuchus pallidicinctus). ${ }^{13}$ Woody plant expansion in the Great Plains is associated with loss of grassland biodiversity including the decline of grassland birds, ${ }^{11,13}$ the fastest declining bird guild in North America. ${ }^{14}$ Ironically, conservation programs that plant eastern redcedar in prairies conflict with efforts to limit prairie fragmentation and maintain prairie biodiversity and ecosystem function.

\section{Conservation Enigmas Associated With Tree Planting Using Native Species}

Tree planting programs supported by conservation agencies are perhaps the most enigmatic element of tree encroachment in North American grasslands, especially when trees are planted by an agency that also administers programs to remove trees from grasslands. For example, the Natural Resource Conservation Service in Oklahoma recently administered conservation programs encouraging tree planting while also administering federal cost-share conservation programs removing eastern redcedar from grasslands. This apparent contradiction in conservation practices sends the public a mixed message and otherwise detracts from conservation efforts.

Additional problems stem from the dispute and confusion within the scientific community that excludes native species from classification as potentially invasive simply because native species are indigenous to the continent. ${ }^{15}$ This position ignores the fact that endemic species with a wide amplitude of environmental tolerances are potentially invasive when barriers to their expansion are removed. ${ }^{2}$ Encroachment by native species and invasion by 
Table 1. State nurseries ${ }^{a}$ that distribute eastern redcedar seedlings as a conservation species in the United States

\begin{tabular}{|c|c|c|c|c|c|}
\hline \multirow[b]{2}{*}{ State } & \multicolumn{2}{|c|}{$\begin{array}{l}\text { Eastern redcedar } \\
\text { seedlings distributed }\end{array}$} & \multirow[b]{2}{*}{$\begin{array}{l}\text { No. of years } \\
\text { distributing }\end{array}$} & \multirow[b]{2}{*}{$\begin{array}{l}\text { Cost (US\$)/ } \\
\text { seedling }\end{array}$} & \multirow[b]{2}{*}{ Purpose } \\
\hline & 2001 & $\begin{array}{l}\text { Annual } \\
\text { average }\end{array}$ & & & \\
\hline Colorado & 200,000 & 200,000 & 44 & $0.40-1.00$ & windbreaks \\
\hline Connecticut & 4,000 & 4,000 & 6 & 0.50 & wildlife habitat, windbreaks \\
\hline Georgia & 50,000 & 75,000 & $>41$ & $0.50-1.00$ & privacy fencing, Christmas trees \\
\hline Indiana & 0 & 10,000 & 15 & 0.17 & erosion control, windbreaks, mine reclamation \\
\hline lowa & 93,200 & 100,000 & 20 & 0.20 & wildlife habitat, erosion, shelterbelts \\
\hline Kansas & 155,000 & 115,000 & 44 & $0.56-1.37$ & windbreaks, wildlife habitat \\
\hline Maryland & 20,000 & 50,000 & 6 & $0.04-0.12$ & windbreaks, privacy fencing, duck blinds \\
\hline Minnesota & 19,800 & 98,000 & 41 & 0.18 & shelterbelts, windbreaks, wildlife habitat \\
\hline Missouri & 70,000 & 100,000 & 53 & 0.16 & windbreaks, wildlife habitat \\
\hline Nebraska & 511,373 & 850,000 & 76 & $0.36-0.62$ & windbreaks, living snow fences, wildlife habitat \\
\hline Nevada & 368 & 400 & $-\mathrm{b}$ & 1.40 & windbreaks \\
\hline New Mexico & 7,000 & 7,500 & $15-20$ & $0.85-2.10$ & farmsteads, livestock protection, windbreaks \\
\hline New York & 25,000 & 25,000 & 15 & 0.30 & windbreaks, beach stabilization, wildlife habitat \\
\hline North Carolina & 274,500 & 275,000 & $>40$ & 0.20 & privacy fencing, windbreaks \\
\hline North Dakota & 198,000 & 200,000 & $-\mathrm{b}$ & $0.19-0.50$ & windbreaks \\
\hline Ohio & 0 & 17,500 & $<5$ & $0.24-0.35$ & mine reclamation, private landowner uses \\
\hline Oklahoma & 70,000 & 85,000 & 54 & $0.27-0.35$ & windbreaks, living snow fences \\
\hline South Carolina & 80,000 & 78,500 & $>20$ & $0.20-0.50$ & reforestation, Christmas trees \\
\hline South Dakota & 500,000 & 500,000 & 43 & 0.45 & windbreaks, wildlife habitat, $\mathrm{CRP}^{\mathrm{c}}$ plantings \\
\hline Texas & 17,500 & 23,500 & 20 & $1.20-1.73$ & windbreaks \\
\hline Utah & 5,275 & 5,000 & 23 & 0.76 & windbreaks, shelterbelts \\
\hline Virginia & 10,300 & 10,300 & 7 & $0.44-1.20$ & $\begin{array}{l}\text { windbreaks, fencing, erosion control, wildlife } \\
\text { habitat }\end{array}$ \\
\hline Total & $2,311,316$ & $2,829,700$ & & & \\
\hline \multicolumn{6}{|c|}{$\begin{array}{l}\text { aConservation districts typically obtain their seedlings from state nurseries, so data from conservation districts are not } \\
\text { included. } \\
\text { bInformation not available. }\end{array}$} \\
\hline
\end{tabular}

nonindigenous species, distinguished only because of semantic arguments based on geographic origin, ${ }^{15}$ operate through identical ecological processes. Ignoring or misunderstanding the functional similarity between nonindigenous invasion and native encroachment may lead to the perception that native plant species are always benign. Yet, under certain conditions where limiting factors (e.g., fire, grazing, disease) have been altered or removed, native species encroach into new ecosystems.
Failure to recognize or consider the invasive potential of eastern redcedar may be a reason for the long history of liberal transportation of eastern redcedar seeds and seedlings throughout the United States (Fig. 1). Many states that we surveyed trade or sell eastern redcedar seedlings to other states, with the farthest exchange being from North Carolina to California. In general, transportation of nursery stock of any species across state borders is poorly restricted, although several nurseries have voluntarily discontinued growing and 


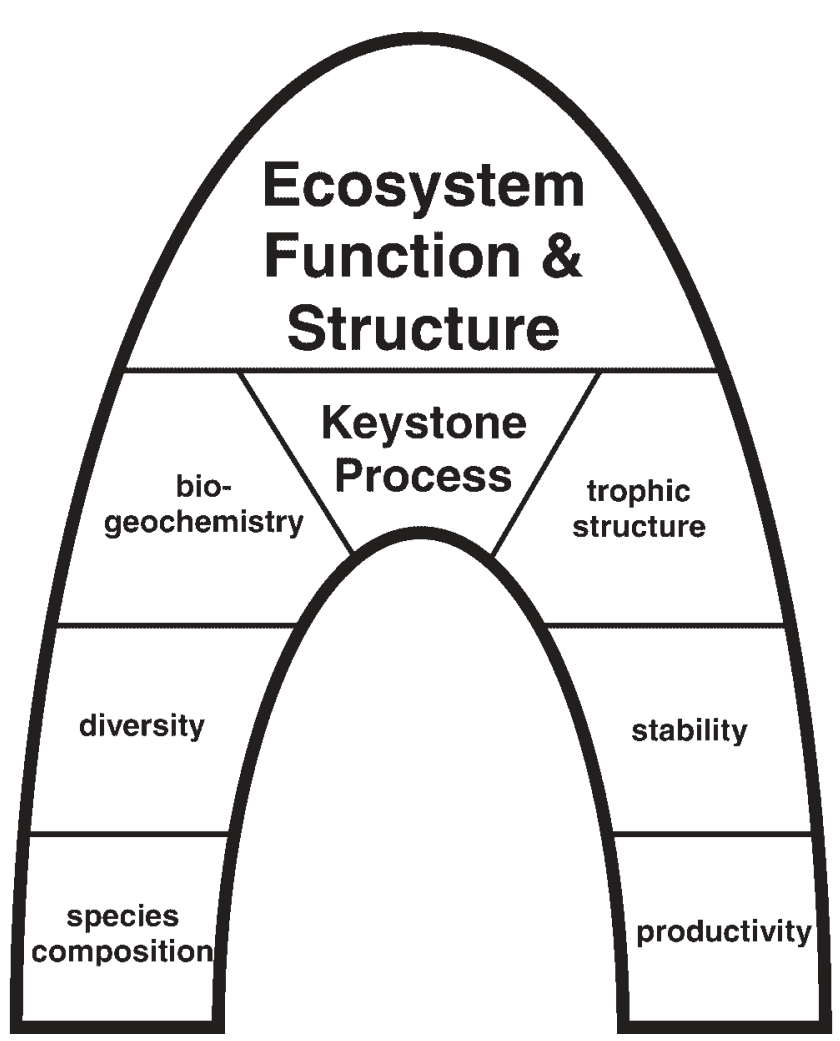

Figure 1. Schematic diagram of the keystone process concept. In an arch, a keystone is the central stone, bearing the lateral and vertical stresses and binding the structure of the arch together. Keystone processes or their exclusion also hold together the arch of ecosystem function and structure. Removal of a keystone process potentially alters ecosystems, including trophic structure, biogeochemistry, diversity, stability, productivity, species composition, and other attributes. For example, in the North American Great Plains the keystone processes of fire and herbivory by large mammals historically maintained the structure and function of prairie ecosystems. ${ }^{19}$

selling nonnative and native plants such as eastern redcedar that pose an invasive threat.

Eastern redcedar exhibits an exceptionally wide range of environmental tolerance. Eastern redcedar thrives in the absence of fire in an environment normally hostile to trees, and it shares other traits common to woody invasive species of plants introduced for horticultural or conservation purposes. Ease of propagation, rapid growth, and high rates of survival ${ }^{16}$ are also traits that make eastern redcedar attractive to landowners and managers, but which also enable eastern redcedar to effectively invade nonnative habitats that include prairie systems.

\section{Native Species Become Invasive When Keystone Processes Are Altered}

Keystone processes such as fire, herbivory, or climate maintain ecosystem function and structure, and altering, adding, or removing any of these processes may alter properties of ecosystems to include increasing susceptibility to invasion or encroachment, even by native species historically absent from the site. When evaluating the potential invasiveness of a native species for use in conservation planting programs, we recommend that agencies strive to retain the functional keystone processes that maintain core ecosystem dynamics. Expansion of many native woody species in North America can be attributed to human alteration of keystone processes (Fig. 1) that presented barriers to species distribution and abundance (see review by Archer 19944).

In the Great Plains, eastern redcedar distribution is directly influenced by keystone processes (i.e., fire and grazing). Eastern redcedar was historically excluded throughout the Great Plains by natural and anthropogenic fire except on isolated sites too rough or too shallow to produce sufficient fuel to carry fire. ${ }^{6}$ Fire suppression throughout the Great Plains is a major factor contributing to the substantial encroachment by eastern redcedar in this region. ${ }^{11}$ Because fire no longer operates through most of the Great Plains grasslands, planting eastern redcedar is likely to result in encroachment into native grassland remnants in the region.

Encroachment of honey mesquite (Prosopis glandulosa) into grasslands of the American Southwest represents yet another consequence of altered keystone processes with respect to the expansion of native woody plants in grasslands. Honey mesquite, a woody plant native to the southwestern United States, has increased in distribution and abundance in some grassland and savanna ecosystems following the addition of one keystone process (dispersal through livestock grazing) and the removal of another keystone process (herbivory removal and suppression by black-tailed prairie dog [Cynomys ludovicianus]). Although honey mesquite has not been part of conservation tree planting programs, it illustrates the consequences of altering keystone processes ${ }^{5}$ and the resulting invasion by a native species.

The impact of removing keystone processes has long been appreciated with native animals but not plants. For example, an ecological equivalent to planting eastern redcedar in areas where the keystone process (i.e., fire) were removed is introduction of an ungulate (e.g., white-tailed deer [Odocoileus virginianus]) in areas where the keystone predation processes, including human hunting, was removed. Predation was the keystone process that limited population size; consequently, the removal of predation ultimately leads to rapid population growth until resources become limiting. In general, risks associated with introducing a native herbivore are often taken into consideration as compared to the poorly understood and often-ignored risks associated with native plants.

\section{Assessing the Risk of Native Species Used in Conservation Programs}

We suggest employing a risk assessment approach for evaluating whether or not native species might encroach into ecosystems where ecological barriers are removed (Fig. 2). Risk assessment is a process in which invasive characteristics 


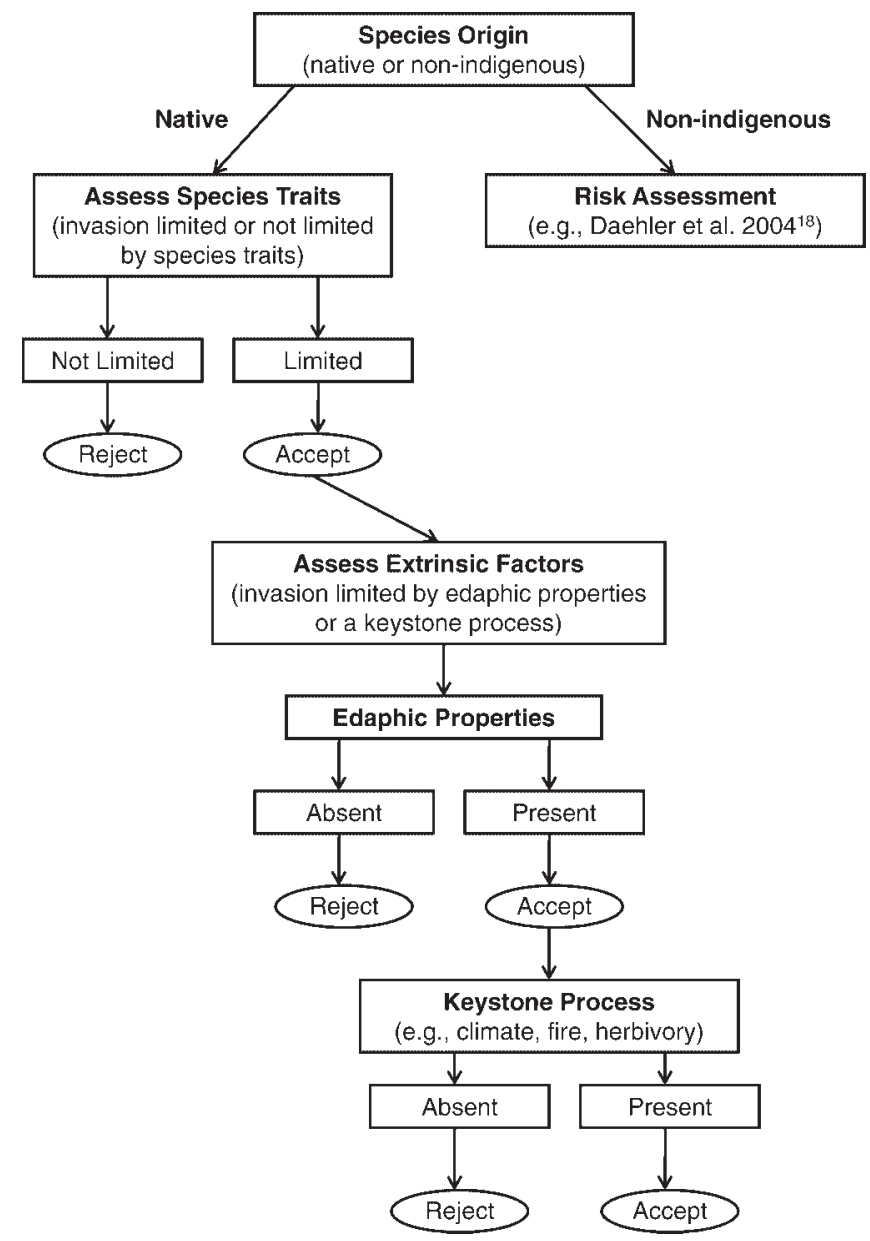

Figure 2. Proposed conceptual framework for evaluating native and nonindigenous species used in conservation plantings. In this framework, nonindigenous species are evaluated through established risk assessment protocols, and native species are evaluated through assessing the presence or absence of limiting factors such as species traits and extrinsic factors (soil properties and keystone processes). Species traits (limiting or non-limiting) and extrinsic factors (absent or present) are used to evaluate acceptability of the species for conservation planting.

of species are identified and used to construct screening protocols for potentially invasive species. Although risk assessment has been used to successfully screen nonindigenous species, ${ }^{17,18}$ risk assessment has rarely been used to assess the encroachment potential of native species (i.e., those species historically found in a defined geographic area or ecosystem).

We propose an additional screening framework (Fig. 2, left pathway) for evaluating the encroachment risk of native species proposed for use in conservation programs. In this framework, native species are assessed by evaluating extrinsic (soil properties and keystone processes) limiting factors and intrinsic species traits. A native species poses little risk of encroachment if the species is limited by species traits such as low growth rate, shade intolerance, low seed viability, or absence of seedling establishment. If soil properties (e.g., soil texture, soil depth, resource availability, topography) limit the distribution and abundance of a species, the risk of encroachment will be low in areas where the limiting soil properties exist, but high in areas where the limiting soil properties do not exist. For example, cottonwood (Populus deltoides) is a native tree limited to moist soils in much of the western Great Plains, thus risk of encroachment of cottonwood is low on upland sites. In contrast, eastern redcedar is a native species with a wide tolerance to a variety of soil properties; thus, risk of invasion is high on many sites. Species (e.g., eastern redcedar and honey mesquite) limited by a keystone process that has been removed have high potential for encroachment and should not be considered for use in conservation plantings. However, if an intact keystone process will limit spread of a species, the risk of encroachment is low and the species is acceptable for use in conservation plantings.

Existing "weed" risk assessment protocols would have little value in predicting encroachment by native species because current protocols fail to incorporate the presence of keystone processes that historically limited the distribution of native species. Weed risk assessments are limited generally to questions regarding history and biogeography, undesirable characteristics, and biology and ecology of the species under evaluation. Weed risk assessment protocols are fast, objective, cost-efficient, and adaptable for any number of invasive species of any region, ${ }^{18}$ so elements of the risk assessment framework should be considered for incorporation into risk assessments for potentially encroaching native species.

\section{Summary}

No species, native or nonindigenous, should be used in planting programs without considering its invasive potential (i.e., by risk assessment). Increased dispersal from tree planting can be the catalyst in converting grassland to woodland when accompanied by change in ecosystem keystone processes. Consequently, tree planting in North American prairie represents a contradiction to conservation of imperiled prairie ecosystems. Indeed, woody plant invasions resulting from introduction of species for aesthetics, conservation, and agroforestry is a global problem. ${ }^{16,17}$ If conservation of native species and native grasslands is considered an important goal in conservation, then programs and activities that facilitate the spread of invasive species, both native and nonindigenous, should be curtailed.

\section{References}

1. Binggeli, P. 1996. A taxonomic, biogeographical and ecological overview of invasive woody plants. Journal of Vegetation Science 7:121-124.

2. Johnstone, I. M. 1986. Plant invasion windows: a time-based classification of invasion potential. Biological Review 61: 369-394.

3. Rejmánek, M., and D. M. Richardson. 1996. What attributes make some plant species more invasive? Ecology 77:1655-1661. 
4. Archer, S. 1994. Woody plant encroachment into southwestern grasslands and savannas: rates, patterns and proximate causes. In: M. Vavra, W. Laycock, and R. Pieper [EDs.]. Ecological implications of livestock herbivory in the west. Denver, CO, USA: Society for Range Management. p. 13-68.

5. Weltzin, J. F., S. Archer, and R. K. Нeitschmidt. 1997. Small-mammal regulation of vegetation structure in a temperate savanna. Ecology 78:751-763.

6. Bragg, T. B., and L. C. Hulbert. 1976. Woody plant invasion of unburned Kansas bluestem prairie. Journal of Range Management 29:19-24.

7. Olson, T. E., And F. L. Knopf. 1986. Agency subsidization of a rapidly spreading exotic. Wildlife Society Bulletin 14:492-493.

8. Samson, F., and F. Knopf. 1994. Prairie conservation in North America. Bioscience 44:418-421.

9. Droze, W. H. 1977. Trees, prairies and people: a history of tree planting in the Plains States. Denton, TX, USA: Texas Woman's University. 313 p.

10. Coppedge, B. R., D. M. Engle, R. E. Masters, and M. S. Gregory. 2001. Avian responses to landscape change in fragmented southern Great Plains grasslands. Ecological Applications 11:47-59.

11. Ноch, G. A., J. M. Briggs, and L. C. Johnson. 2002. Assessing the rate, mechanisms, and consequences of the conversion of tallgrass prairie to Juniperus virginiana forest. Ecosystems 5:578-586.

12. Norris, M. D., J. M. Blair, L. C. Johnson, and R. B. McKane. 2001. Assessing changes in biomass, productivity, and $\mathrm{C}$ and $\mathrm{N}$. stores following Juniperus virginiana forest expansion into tallgrass prairie. Canadian Journal of Forest Research 31:1940-1946.

13. Fuhlendorf, S. D., A. J. W. Woodward, D. M. Leslie, Jr., AND J. S. Shackford. 2002. Multi-scale effects of habitat loss and fragmentation on lesser prairie-chicken populations of the US Southern Great Plains. Landscape Ecology 17:617-628.

14. Knopf, F. L. 1994. Avian assemblages on altered grasslands. Studies in Avian Biology 15:247-257.

15. Richardson, D. M., P. Pyšek, M. Rejmánek, M. G. Barbour, F. D. Panetta, and C. J. West. 2000. Naturalization and invasion of alien plants: concepts and definitions. Diversity and Distributions 6:93-107.
16. Richardson, D. M. 1998. Forestry trees as invasive aliens. Conservation Biology 12:18-26.

17. Rouget, M., D. M. Richardson, J. L. Nel, and B. W. Van Wilgen. 2002. Commercially important trees as invasive aliens - towards spatially explicit risk assessment at a national scale. Biological Invasions 4:397-412.

18. Daehler, C. C., J. S. Denslow, S. Ansari, and H. C. Kuo. 2004. A risk-assessment system for screening out invasive pest plants from Hawaii and other Pacific Islands. Conservation Biology 18:360-368.

19. Fuhlendorf S. D., and Engle D. M. 2001. Restoring heterogeneity on rangelands: ecosystem management based on evolutionary grazing patterns. Bioscience 51: 625-632.

Authors are Post-doctoral Research Ecologist, US Dept of Agriculture Forest Service, Rocky Mountain Research Station, Boise, ID 83702, USA, amyganguli@gmail.com (Ganguli); Professor, Dept of Natural Resource Ecology and Management, 339 Science II, Oklahoma State University, Stillwater, OK 74078, USA (Engle); Ecologist, US Environmental Protection Agency, National Risk Management Research Lab, 919 Kerr Research Drive, Ada, OK 74820, USA (Mayer); and Professor, Dept of Natural Resource Ecology and Management, Stillwater, OK 74078, USA (Fublendorf). The US Environmental Protection Agency (Agency) through its Office of Research and Development partially funded and collaborated in the research described here under an interagency agreement ( $D W-14-$ 93900001-1) with the Biological Resources Division of the United States Geological Survey (USGS), administered by the Oklahoma Cooperative Fish and Wildlife Research Unit located at Oklahoma State University (USGS, Oklahoma State University, Oklahoma Department of Wildlife Conservation, and Wildlife Management Institute cooperating). The research described here has not been subjected to Agency review and therefore does not necessarily reflect the viewus of the Agency or USGS, and no official endorsement should be inferred. The Oklahoma Agricultural Experiment Station also provided support to the first two authors. This article is published with the approval of the director, Oklahoma Agricultural Experiment Station. 